\title{
The effects of meteorological parameters and diffusive barrier reuse on the sampling rate of a passive air sampler for gaseous mercury
}

David S. McLagan et al.

Correspondence to: Frank Wania (frank.wania@utoronto.ca)

The copyright of individual parts of the supplement might differ from the CC BY 3.0 License. 


\section{S1: Wind speed experiments: setup and regression coefficients}
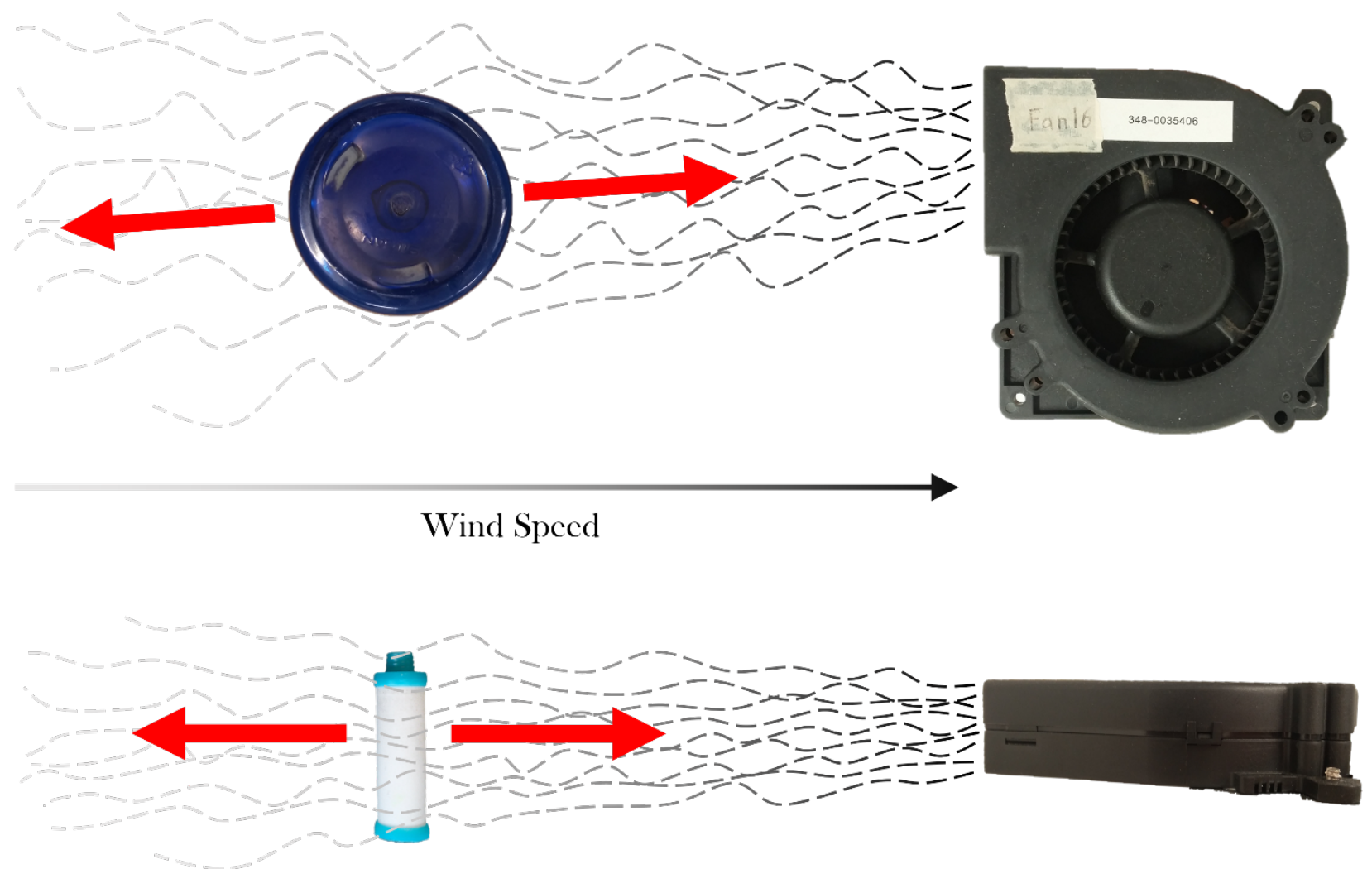

Figure S1: Graphical representations of the experimental setup used to study the impact of wind speed on the sampling rate of the passive air sampler (PAS). An overhead view of the PAS with protective shield is shown on the top and a side-on view of the PAS without protective shield below. A previous detailed mapping of the wind field generated by the fans revealed greater wind speed closer to the fan (Zhang et al., 2013). Therefore wind speed can be adjusted by varying the distance between PAS and the fans. Wind speeds were recorded at the front of each individual PAS (with the PAS removed) before and after each deployment for 5 minutes.

TABLE S1: Coefficients and standard error of slope and y-intercept examining the effect of wind speed on sampling rate relationships in Figure 1 of main text.

\begin{tabular}{llrrrr}
\hline \hline \multicolumn{1}{c}{ Radiello Type } & Protective shield & \multicolumn{1}{c}{ Slope } & Standard error & Y-intercept & Standard error \\
\hline \hline White & Yes (all data) & 0.0079 & 0.0008 & 0.1132 & 0.0027 \\
White & Yes (data $>1 \mathrm{~m} \mathrm{~s}^{-1}$ ) & 0.0028 & 0.0010 & 0.1367 & 0.0041 \\
White & No & 0.0221 & 0.0011 & 0.1025 & 0.0042 \\
Yellow & Yes & 0.0014 & 0.0018 & 0.0568 & 0.0070 \\
Yellow & No & 0.0022 & 0.0012 & 0.0689 & 0.0050 \\
\hline \hline
\end{tabular}




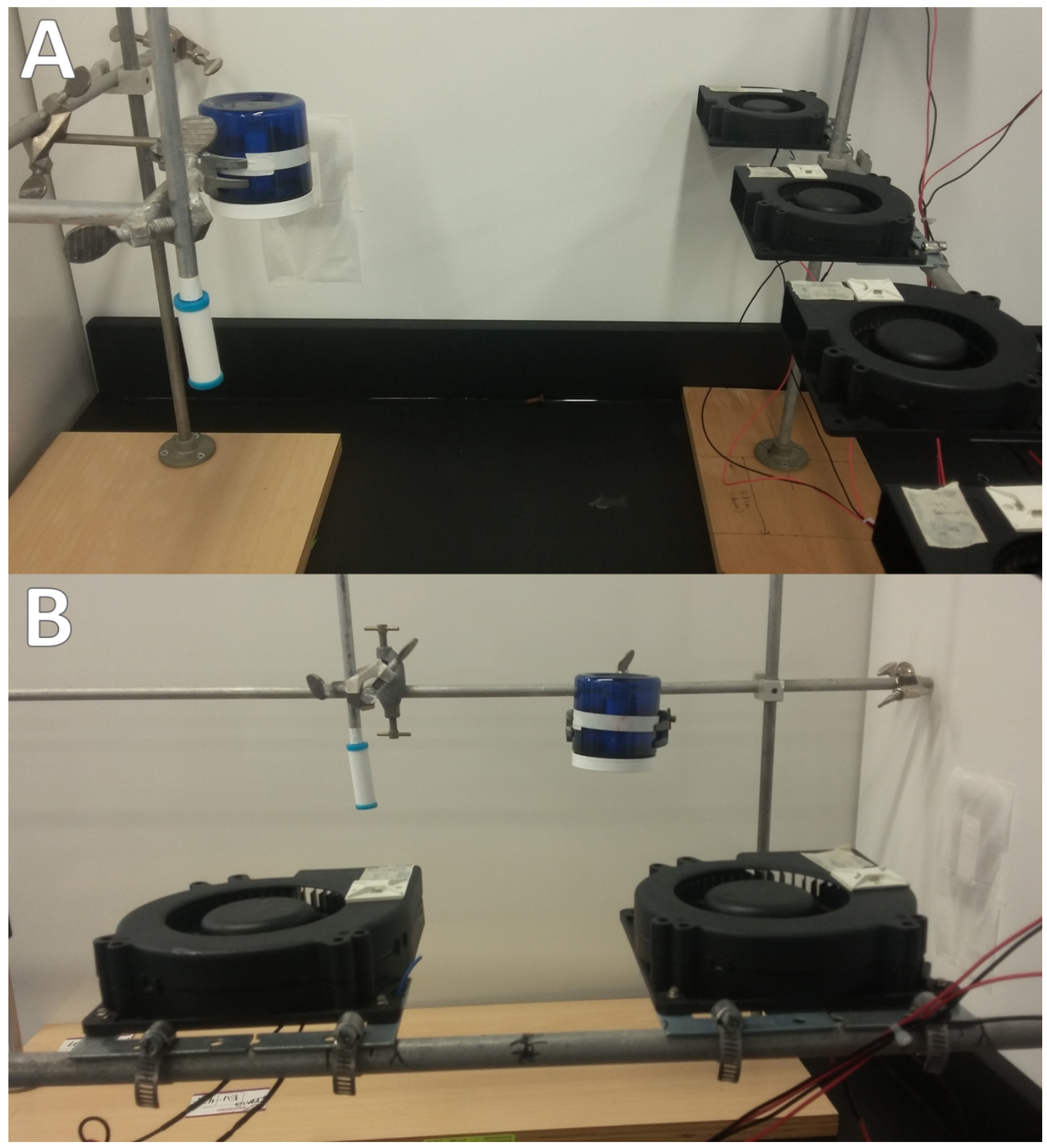

Figure S2: Images of PAS setup for wind experiments. Changes in windspeed were achieved by adjusting boss head and clamps allowing movement in $X, Y$, and $Z$ spatial dimensions on retort stands. Panel A: Side view of experimental setup with electronic fans and Config. 1 (white Radiello, with protective shield; right) and Config. 2 (white Radiello, without protective shield; left) PASs. Panel B: Rear view of experimental setup. 


\section{S2: Dust coating of Radiellos ${ }^{\circledR}$ and corresponding sorbed mercury for each sampler in Radiello ${ }^{\circledR}$ reuse experiment}

Table S2: Indoor experiment on the variability of $\mathrm{Hg}$ uptake in previously deployed Radiellos. Mass of sorbed mercury (ng) and visually assessed extent of dust coating of the Radiellos prior to different cleaning treatments (scale: 0 - new, 1 - very low, 2 -low, 3 - moderate, 4 - high, and 5 - very high).

\begin{tabular}{|c|c|c|c|c|c|c|c|c|c|c|c|c|c|c|}
\hline \multirow{2}{*}{$\begin{array}{c}\text { Replicat } \\
\text { e }\end{array}$} & \multicolumn{2}{|c|}{ New } & \multicolumn{2}{|c|}{ Uncleaned } & \multicolumn{2}{|c|}{ Physical } & \multicolumn{2}{|c|}{ Soap } & \multicolumn{2}{|c|}{ Acid } & \multicolumn{2}{|c|}{ Heat-acid } & \multicolumn{2}{|c|}{ Memory } \\
\hline & $\begin{array}{l}\text { Sorbed } \\
\mathrm{Hg}\end{array}$ & $\begin{array}{c}\text { Dust } \\
\text { coating }\end{array}$ & $\begin{array}{c}\text { Sorbed } \\
\mathrm{Hg}\end{array}$ & $\begin{array}{c}\text { Dust } \\
\text { coating }\end{array}$ & $\begin{array}{c}\text { Sorbed } \\
\mathrm{Hg}\end{array}$ & $\begin{array}{c}\text { Dust } \\
\text { coating }\end{array}$ & $\begin{array}{c}\text { Sorbed } \\
\mathrm{Hg}\end{array}$ & $\begin{array}{c}\text { Dust } \\
\text { coating }\end{array}$ & $\begin{array}{c}\text { Sorbed } \\
\mathrm{Hg}\end{array}$ & $\begin{array}{c}\text { Dust } \\
\text { coating }\end{array}$ & $\begin{array}{c}\text { Sorbed } \\
\mathrm{Hg}\end{array}$ & $\begin{array}{c}\text { Dust } \\
\text { coating }\end{array}$ & $\begin{array}{c}\text { Sorbed } \\
\mathrm{Hg}\end{array}$ & $\begin{array}{c}\text { Dust } \\
\text { coating }\end{array}$ \\
\hline A & 23.7 & 0 & 23.3 & 2 & 14.4 & 5 & 22.1 & 3 & 22.1 & 4 & 21.9 & 1 & 23.4 & 3 \\
\hline B & 18.4 & 0 & 22.5 & 4 & 22.7 & 1 & 21.4 & 2 & 23.6 & 4 & 23.0 & 3 & 24.7 & 3 \\
\hline C & 18.5 & 0 & 9.0 & 5 & 19.2 & 2 & 18.1 & 1 & 23.9 & 5 & 19.9 & 2 & 18.1 & 3 \\
\hline D & 19.2 & 0 & 17.9 & 1 & 18.0 & 2 & 19.3 & 2 & 19.2 & 4 & 17.0 & 3 & 18.8 & 3 \\
\hline $\mathrm{E}$ & 23.3 & 0 & 16.6 & 3 & 17.9 & 3 & 18.7 & 4 & 18.9 & 2 & 21.2 & 4 & 20.2 & 3 \\
\hline Avg. & 20.6 & 0.0 & 17.9 & 3.0 & 18.4 & 2.6 & 19.9 & 2.4 & 21.5 & 3.8 & 20.6 & 2.6 & 21.0 & 3.0 \\
\hline SD & 2.7 & & 5.7 & & 3.0 & & 1.7 & & 2.4 & & 2.3 & & 2.9 & \\
\hline RSD & $13 \%$ & & $32 \%$ & & $16 \%$ & & $9 \%$ & & $11 \%$ & & $11 \%$ & & $14 \%$ & \\
\hline
\end{tabular}

Table S3: Outdoor experiment on the variability of $\mathrm{Hg}$ uptake in previously deployed Radiellos. Mass of sorbed mercury (ng) and visually assessed extent of dust coating of the Radiellos prior to cleaning (scale: 0 - new, 1 - very low, 2 - low, 3-moderate, 4 - high, and 5 - very high).

\begin{tabular}{|c|c|c|c|c|c|c|}
\hline \multirow[b]{2}{*}{ Replicate } & \multicolumn{2}{|c|}{ New } & \multicolumn{2}{|c|}{ Uncleaned } & \multicolumn{2}{|c|}{ Soap } \\
\hline & Sorbed Hg & Dust coating & Sorbed $\mathrm{Hg}$ & Dust coating & Sorbed Hg & Dust coating \\
\hline A & 7.4 & 0 & 6.7 & 5 & 7.3 & 5 \\
\hline B & 7.4 & 0 & 7.4 & 4 & 7.7 & 5 \\
\hline C & 7.5 & 0 & 7.0 & 5 & 7.4 & 4 \\
\hline D & 7.7 & 0 & 7.2 & 4 & 7.5 & 4 \\
\hline $\mathrm{E}$ & 7.1 & 0 & 7.9 & 4 & 7.3 & 5 \\
\hline Avg. & 7.4 & 0.0 & 7.3 & 4.4 & 7.5 & 4.6 \\
\hline SD & 0.2 & & 0.5 & & 0.2 & \\
\hline RSD & $3 \%$ & & $6 \%$ & & $2 \%$ & \\
\hline
\end{tabular}




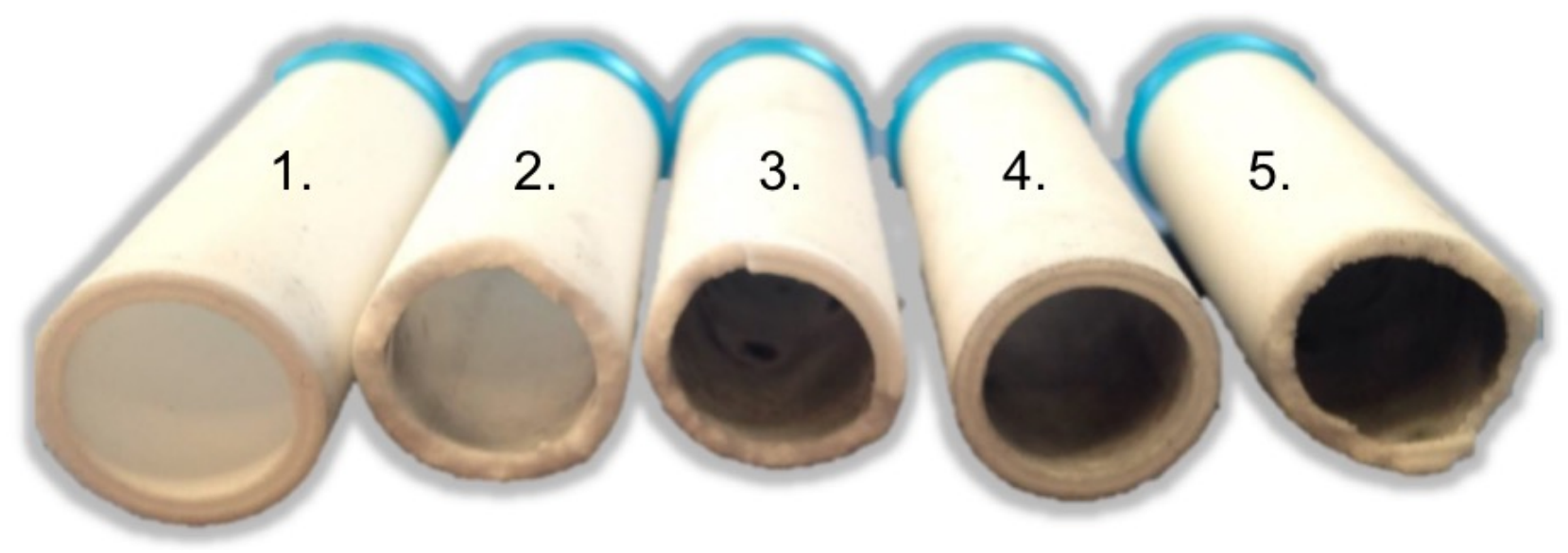

Figure S3: Categorical 1-5 ranking of HGR-AC dust coating inside Radiellos ${ }^{\circledR}$ prior to cleaning (scale: 0 new, 1 - very low, 2 - low, 3-moderate, 4- high, and 5 - very high). 


\section{S3: Effect of deployment time on sampling rate for wind speed experiments}

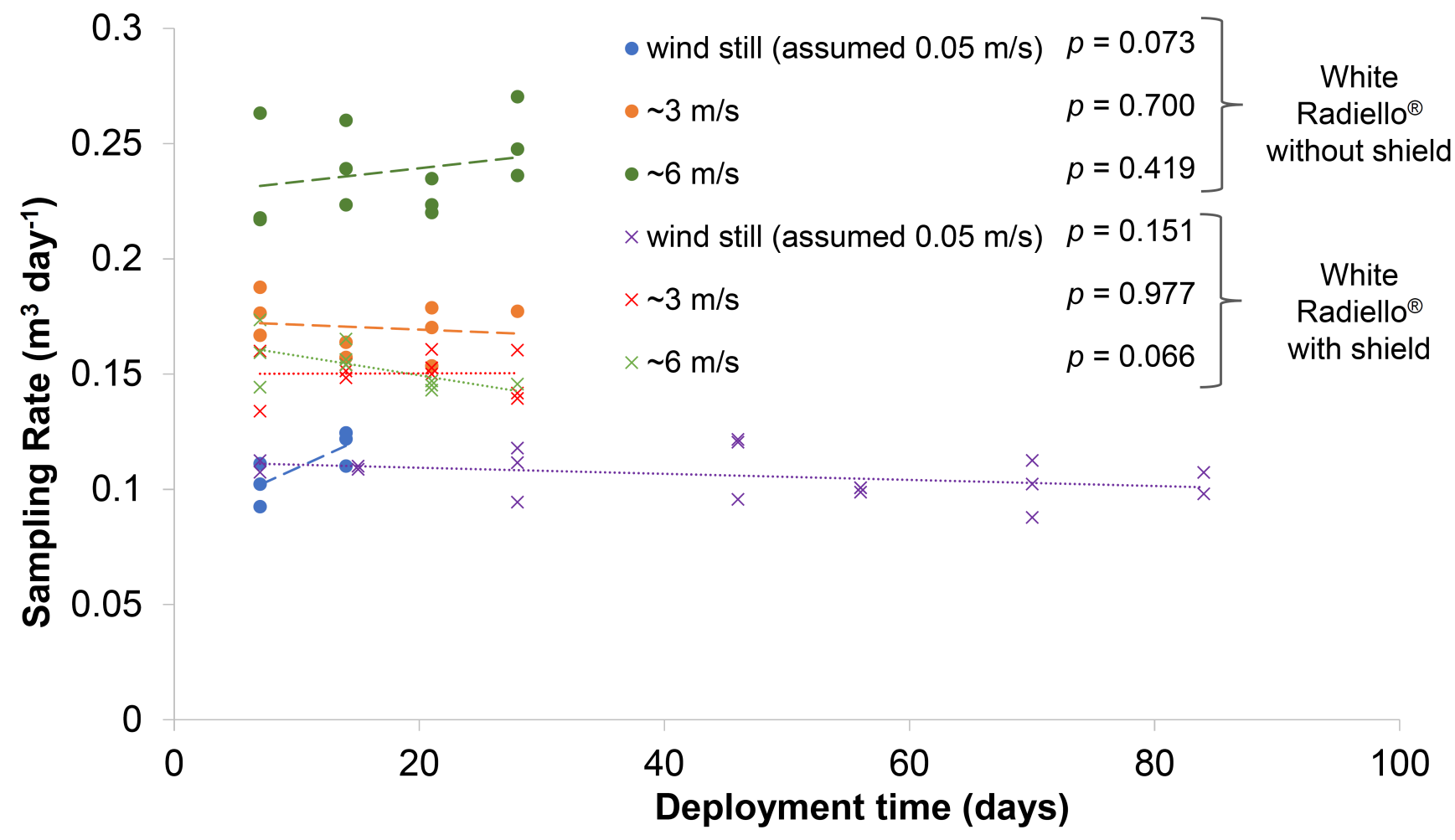

Figure S4: Uptake experiments: Sampling rate (SR) after different deployment times for PAS configuration 1 and 2 (white Radiello ${ }^{\circledR}$, with and without protective shield, respectively) deployed at wind still (assumed $0.05 \mathrm{~m} \mathrm{~s}^{-1}$ ) conditions and at wind speeds of $\sim 3 \mathrm{~m} \mathrm{~s}^{-1}$ and $\sim 6 \mathrm{~m} \mathrm{~s}^{-1}$. In none of these experiments did the $S R$ vary significantly with deployment time. 
S4: Uptake curve for indoor uptake and calibration experiment using white Radiello ${ }^{\circledR}$ with protective shield

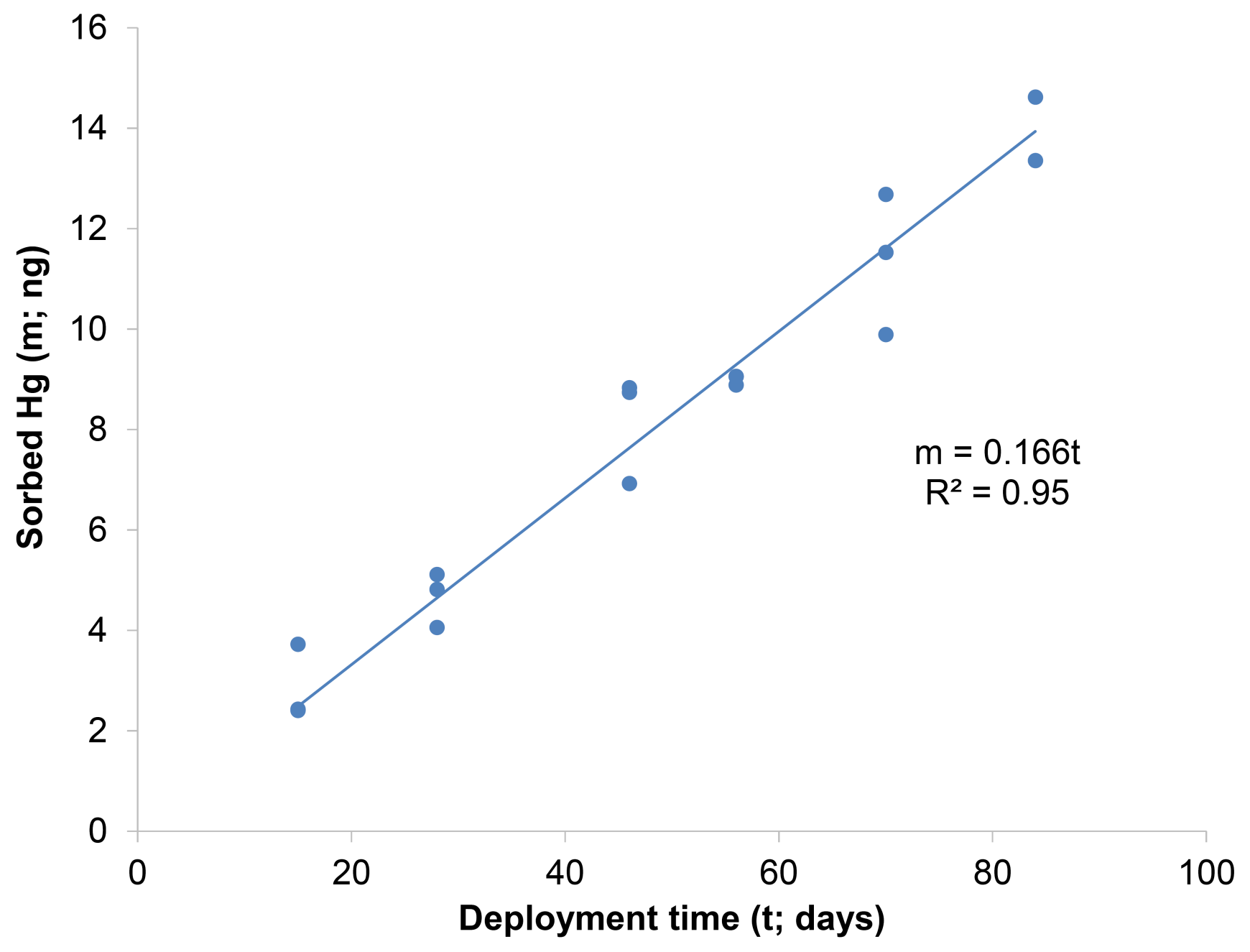

Figure S5: Uptake curve for indoor experiment at wind still conditions using standard configuration PAS (white Radiello ${ }^{\circledR}$ with protective shield). The mean gaseous $\mathrm{Hg}$ concentration measured by the Tekran 2537A was $1.63 \pm 0.15 \mathrm{ng} \mathrm{m}^{-3}$. 


\section{S5: Effect of relative humidity on sampling rate}

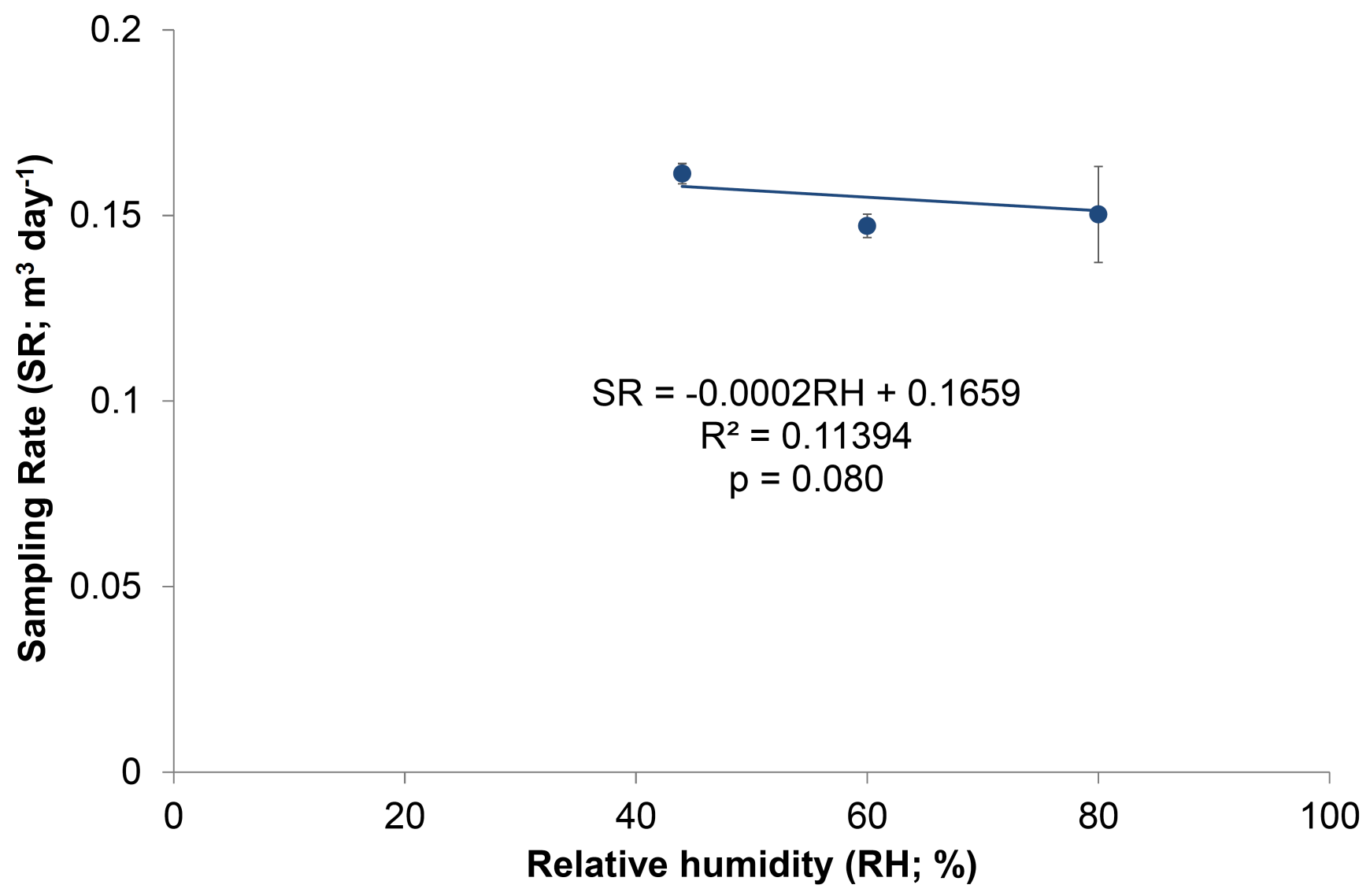

Figure S6: Effect of relative humidity $(\mathrm{RH})$ on SR of the passive air sampler for gaseous mercury as determined in chamber experiments. Temperature was held constant at $20^{\circ} \mathrm{C}$ throughout the experiments and wind speeds ranged between 1.1 and $2.3 \mathrm{~m} \mathrm{~s}^{-1}$ when measured over two minute intervals at the position of the samplers both before and after the experiments. No significant effect of $\mathrm{RH}$ on $\mathrm{SR}$ was observed for the range of $44-80 \%(p=0.080)$. 


\section{S5: Effect size using Cohen's d value for Radiello ${ }^{\circledR}$ reuse experiments}

Effect size describes the strength of an effect between two variables. One measure of effect size is Cohen's d, which essentially provides a standardized method for differentiating two means, while also factoring in variance, without the involvement of traditional binary hypotheses testing (Cohen, 1988). Applying Cohen's d test to the cleaning treatments there is very little difference (small or no diff.) between the new and the three cleaning treatments of soap, acid, and heat-acid, while the difference to uncleaned and physical treatments were greater (medium; Table 2).

Table S4: Pairwise comparison table of Cohen's d value for sorbed mercury for each cleaning treatment. Lower comparison contains the effect magnitude ranges based on descriptors from Cohen.37 We use: no diff. $<0.2<$ small $<0.5<$ medium $<0.8<$ large.

\begin{tabular}{l|llcccc} 
& new & uncleaned & physical & soap & acid & heat-acid \\
\hline new & - & 0.616 & 0.777 & 0.314 & 0.362 & 0.008 \\
uncleaned & medium & - & 0.119 & 0.482 & 0.836 & 0.625 \\
physical & medium & no diff. & - & 0.609 & 1.152 & 0.815 \\
soap & small & small & medium & - & 0.778 & 0.336 \\
acid & small & large & large & medium & - & 0.399 \\
heat-acid & no diff. & medium & large & small & small & -
\end{tabular}

Results of Cohen's $d$ test for effect size showed no difference $(d=0.167)$ between new and soap, a small difference between uncleaned and new $(d=0.475)$, and a medium difference between uncleaned and soap $(d=0.598)$ treatments according to the effect magnitude. 


\section{S6: Theoretical sampling rate adjustment equation}

$$
S R_{a d j}=S R_{c a l}+\left(T_{\text {exp }}-T_{c a l}\right) * F_{T}+\left(W S_{\text {exp }}-W S_{c a l}\right) * F_{W S}
$$

Where: $S R_{\text {cal }}-$ is the outdoor calibrated sampling rate $\left(0.121 \mathrm{~m}^{3} \mathrm{day}^{-1}\right)$

$T_{\text {cal }}-$ is the mean temperature from the outdoor calibration experiment $\left(7.6^{\circ} \mathrm{C}\right)$

$W S_{\text {cal }}$ - is the mean wind speed from the outdoor calibration experiment $\left(1.89 \mathrm{~m} \mathrm{~s}^{-1)}\right.$

$F_{\mathrm{T}}-$ is the adjustment factor for temperature $(0.0009$ per $\mathrm{K})$

$F_{\mathrm{Ws}}-$ is the adjustment factor for wind speed $\left(0.003\right.$ per m s$\left.{ }^{-1}\right)$

$S R_{\text {adj }}$ is the adjusted sampling rate for the experiment

$T_{\text {exp }}-$ is the measured mean temperature of the experiment

$W S_{\text {exp }}$ - is the measured mean wind speed of the experiment

\section{Example sampling rate adjustment:}

Lets say the mean measured temperature and wind speed of an experiment are $25.4^{\circ} \mathrm{C}$ and $1.5 \mathrm{~m} \mathrm{~s}^{-1}$ :

$S R_{a d j}=S R_{c a l}+\left(T_{e x p}-T_{c a l}\right) * F_{T}+\left(W S_{\text {exp }}-W S_{c a l}\right) * F_{W S}$

$S R_{a d j}=0.121+(25.4-7.6) * 0.0009+(1.5-1.89) * 0.003$

$S R_{a d j}=0.121+0.0160+(-0.0012)$

$S R_{a d j}=0.136 m^{3} d_{a y}^{-1}$ 


\section{REFERENCES}

Cohen, J.: Statistical power analysis for the behavioural sciences, 2nd ed., Lawrence Erlbaum Associates, Hillsdale, USA, 1988.

Zhang, X., Brown, T. N., Ansari, A., Yeun, B., Kitaoka, K., Kondo, A., Lei, Y. D., and Wania, F.: Effect of wind on the chemical uptake kinetics of a passive air sampler, Environ. Sci. Technol., 47, 7868-7875, 2013. 